\title{
PHYSIOTHERAPY IN INDIA
}

\author{
by HARRY W. Williams, F.R.C.S., \\ Edin. Convener Physiotherapy Sub-Committee \\ Christian Medical Association of India, Chief Medical \\ Officer, Catherine Booth Hospital, Nagercoil.
}

India had a golden age in medicine in the 6th and 7th centuries B.C. and at that time was perfecting empirical treatments in medicine and surgery, some of which are in use even today. The greatest surgeon was Susruta, and in his treatise he gives importance to massage in rehabilitating the injured. Much of the learning of this golden age was lost in the next two millenia but massage continued as an art practised by the village barber, who as in the British Isles was also a surgeon of limited repertoire. Generations of British residents in India have been familiar with the visits of these craftsmen, who added a few minutes pummelling of the scalp and neck to each haircut; pumping the victim for gossip the while, for barbers were the traditional news carriers. In fairness it must be said that they gave one interesting titbits of local news whilst snipping!

I remember a middle-aged Irish business executive who was chronically sick from a congenital abnormality. When I called on him I would of ten find him in the garden clad in bathing slip and stretched on a cane chaise longue - his whole body glistening with oil as the barber worked him all over. It induced in him a great sense of well-being. Of remedial exercise these practitioners knew nothing and the only use of heat I have encountered was in cupping, used particularly on the abdomen. In 1939 the war came to India, at first at a mild tempo but by 1943 camps, training schools, and huge temporary hospitals were springing up all over India. In Poona at 3 I.B.G.H. a large Rehabilitation Department was set up with a pavilion for exercise classes. I remember the gay insouciance of the amputee classes and the plodding competition of 'K NEES $1,2,3$ ' classes presided over by a corporal down-graded to $\mathrm{C}$ - the reason being, I felt, that he was a born physiotherapist. The occupational therapy was exceptionally good, wood work, metal work and leathercraft were taught in the main centre, whilst enthusiastic W.V.S. workers went from ward to ward with all kinds of fancy needlework. Ten miles away was an Indian Base Hospital where a smaller department discovered that traditional prejudice coloured a disabled man's attitudes; leather for example could only be handled by non-caste people, needlework was a tailor's job but knitting was highly popular. To return to Poona-electrotherapy was well represented and the whole was supervised by a few English M.C.S.P.S. With the close of the war this pioneer effort did not bear adequate fruit in civilian practice. The mission hospital to 
which I was appointed in 1939 had a small electrotherapy department with long-wave diathermy, infra-red and U.V.L. lamps. Treatments were given by a doctor or a senior nurse trained by him. This was a common feature in most large hospitals. In 1951 a few missionary institutions had a qualified physiotherapist on the staff and a year or so later a tentative start was made in training Indian personnel. The Victoria Institute for the Blind in Bombay commenced a two-year training for its patients and at the same time 250 miles north, at the. Salvation Army Emery Hospital in Anand, Brigadier Beer, L.C.P.S. (Bom) M.C.S.P., took the first two students for a course based on the M.C.S.P. but reduced to two years. Dr. Beer's story is a remarkable one. He was appointed first to the Emery Hospital as Business Manager. In this capacity he managed the first X-ray machine installed there but felt keenly that the hospital's vital need was more dedicated doctors. So he sat with the boys in the local High School to pass the Bombay Matriculation exam and then proceeded to the College of Physicians and Surgeons, Bombay, for this medical diploma, though by now he was in his middle thirties. It was a proud day for him when he rejoined the staff as a doctor, and a tragedy when a few years later he suffered double detachment of the retina and became blind. But he refused to give up and with the help of the St. Dunstan's Institute he obtained his physiotherapy training and again returned to Anand to develop the embryo electrotherapy section which had been a sideshow of the X-ray Department. A ward dedicated to the memory of Dr. Pennell, the great missionary who was murdered in his

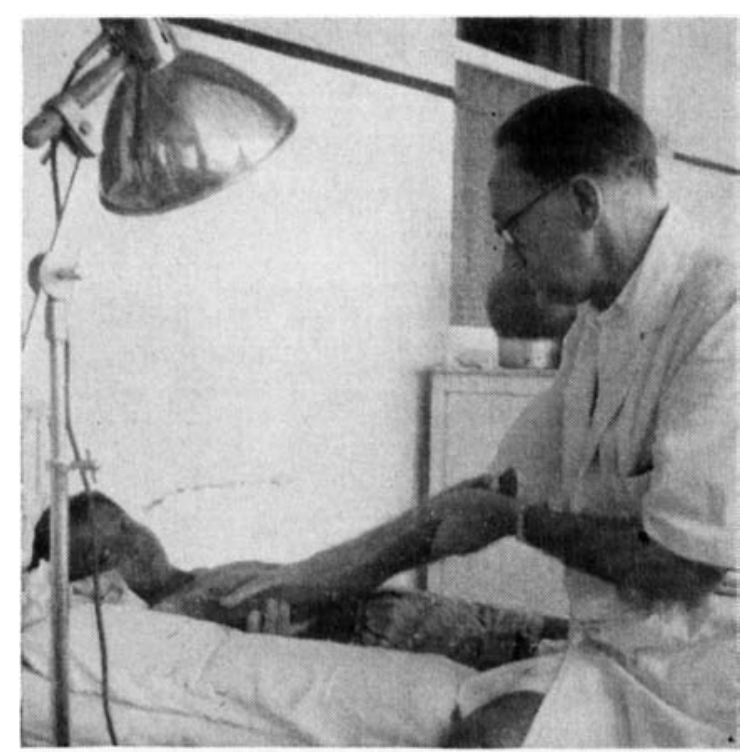

Brigadier Beer giving treatment 


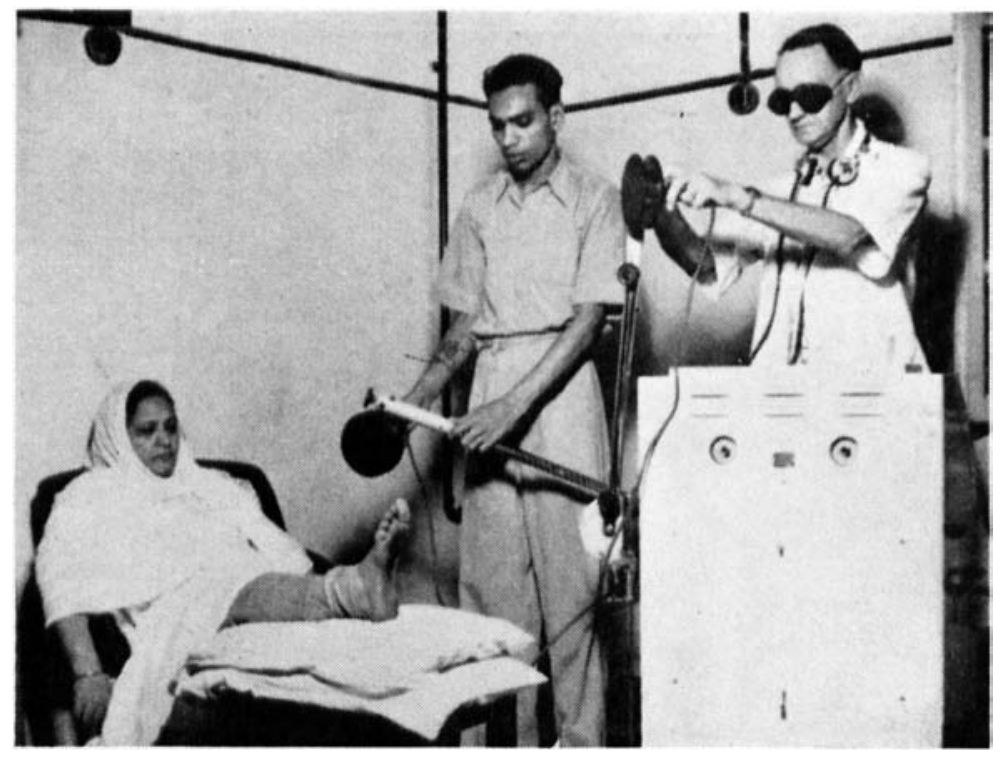

In the Physiotherapy Department

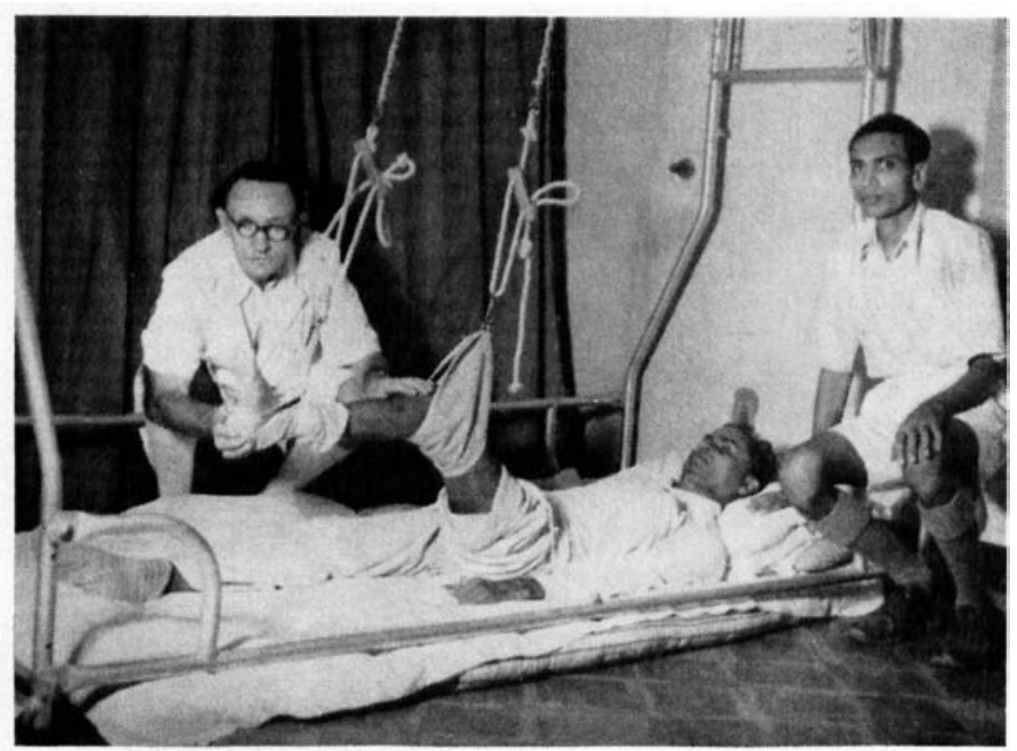

Brigadier Beer giving treatment 


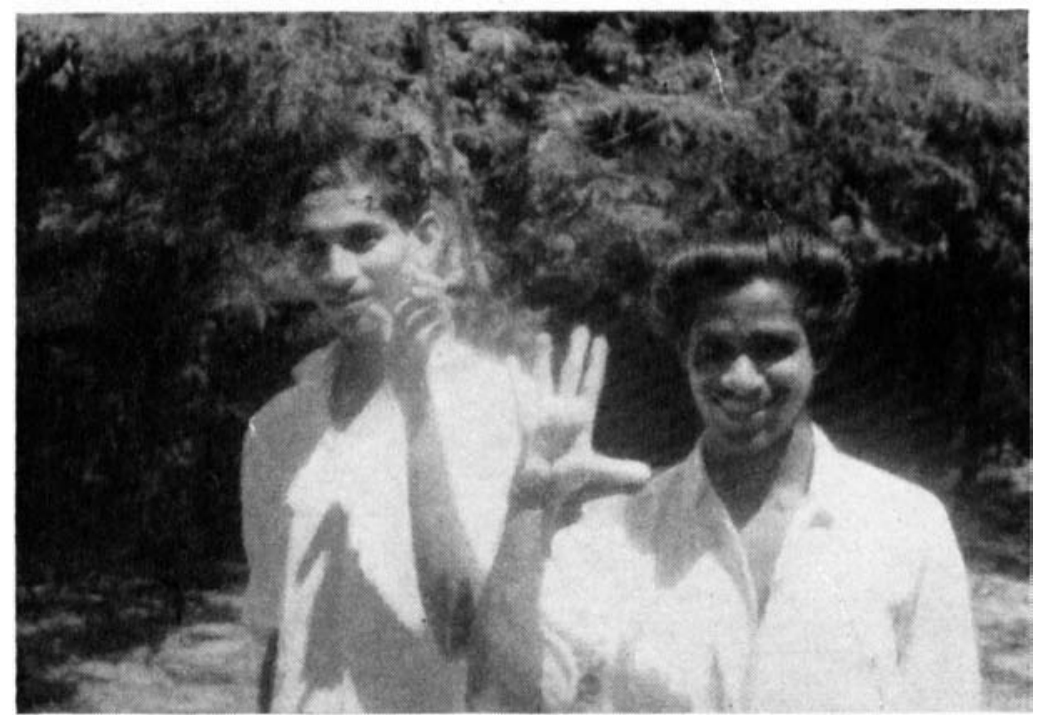

Two hands one with characteristic deformity before operation; the other with full movement after a tendon transplantation operation.

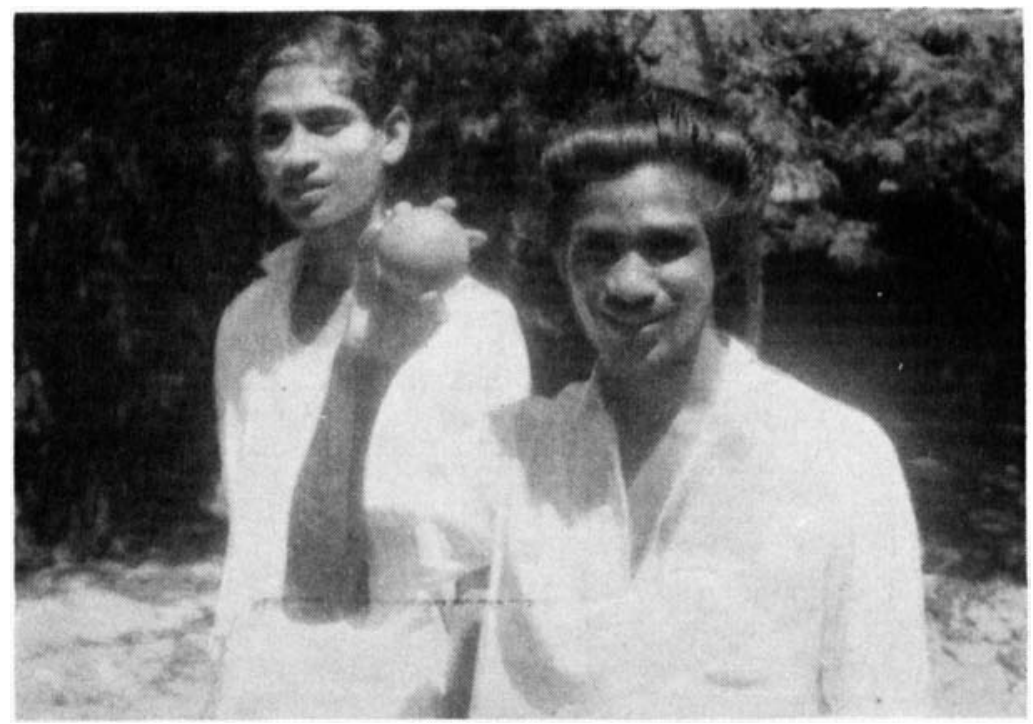

The hand after operation showing normal grip-the loss of this renders the leprosy patient incapable of a handicraft. 
hospital on the N.W. frontier of India, was handed over to Dr. Beer. Redecorated and fitted with cubicles, it was soon busy and gradually outdoor exercise equipment was added and a physiotherapy pool.

Under the persistent enthusiasm of Dr. Beer the Christian Medical Association of India established a physiotherapy subcommittee, inspected the Anand School, and set up an examining body. Stanley Beer died suddenly whilst on holiday in 1956 but the training continued under Captain Roger Wellman, M.C.S.P. and Dr. Beer's first student, Capt. Jethulal. The diploma was recognised by the Indian Association of Physiotherapists. The first graduates went to Ludhiana Medical College, Baroda Medical College and Vellore Christian Medical College in 2 of the $\mathbf{3}$ as the only physiotherapist. By 1957 a fine Rehabilitation Centre was being erected in Bombay under the supervision of Mr. Venton Gough, M.C.S.P. of the W.H.O., and 50 miles north of Anand in the thriving cotton city of Ahmedabad, a beautiful building was under construction . . . but not one physiotherapist was available at that time.

To the Bombay centre has now been added one at Madras and one at Vellore Christian Medical College. These also conduct a two-year course, essentially the same as the one commenced by Dr. Beer. The practice of orthopaedics and reconstructive surgery has made great strides in India since the war and surgeons are well aware of the importance of the physiotherapist's work, but the number available is hopelessly inadequate.

The situation in the Catherine Booth Hospital - the southernmost hospital in India - can well illustrate both the problems and the opportunities. In a 355-bed general hospital a Department of Reconstructive Surgery was opened last year, and to the limited use of electrotherapy (given in a room of the X-ray Department) was added the diagnostic and therapeutic use of faradic and galvanic currents and remedial exercises. It is surprising how much can be done with little money. Fixed bicycle, Guthrie-Smith frame and slings and walking cradles were made by local craftsmen. In January a full Physiotherapy Department was opened, but despite careful search no trained physiotherapist could be found. Eventually one was seconded to us and in addition to organising routine he conducted a three months' practical course for four young assistants with good basic education (Matriculation or Inter Science). These are capable of carrying out routine treatment prescribed in each case by the surgeon or physician. This scheme is working and the staff is fully occupied. On the surgical side much corrective surgery for poliomyelitis is being done, as well as the usual fracture service. This can only be a temporary expedient, for the hospital has about an eighth of the medical staff of a similar British Hospital and the orthopaedic surgeon cannot afford the time. A commencement has 
been made in the reparative surgery of leprosy and no account of physiotherapy in India would be complete without reference to this field. With the advent of sulphone drugs, which are curative in leprosy, reparative surgery became worthwhile. Dr. Paul Brand at Vellore Christian Medical College pioneered tendon transplantation for hand and foot palsies, and a number of plastic surgeons in various parts of the world, experimented with facial repair. These procedures are now standardised and every leprosarium is aware of the need for rehabilitation. The Mission to Lepers has organised a number of six-month courses for workers in this field. In Nagercoil plans have been drawn and funds are being collected to provide separate accommodation for leprosy patients and a department which will give physiotherapy and occupational therapy courses.

The nub of the problem here as elsewhere is staff. It will be a long while before India has enough physiotherapists of her own. Until then she needs foreigners capable of establishing this paramedical science and of teaching Indian students. India welcomes foreigners who come with a primary desire to serve her people. The word 'missionary' is in common use even in Parliament to describe such disinterested service. We need such at Nagarcoil. 